\title{
Vibration-Induced Heating of Energetic Materials: A Review
}

\author{
J. I. Perry ${ }^{1}$ (D) S. M. Walley ${ }^{1}$ \\ Received: 23 March 2021 / Accepted: 5 October 2021 / Published online: 16 November 2021 \\ (c) The Author(s) 2021
}

\begin{abstract}
The transport of energetic materials—-whether by truck over rough terrain, or attached to the undercarriage of a highperformance jet aircraft—carries a certain level of inherent risk as the repeatedly applied stresses from vibration may lead to heating, mechanical degradation, and potentially even the triggering of an ignition event. Increasing knowledge of the underlying physics which control ignition is allowing us to better understand, and thus reduce, the risk of a catastrophic event occurring. The Apollo and Space Shuttle programmes provided motivation for research into the topic in the 1960s and 1970s, and some recent studies have focussed on the grain-scale physics of ignition. However, much of the useful insight has arisen from work with other primary applications in mind. Therefore, this review aims to bring together literature from several fields, with the intention of better understanding vibration-induced heating (VIH) phenomena in energetic materials. Sensitivity, VIH in viscoelastic polymers and inert composites, and a technique known as vibrothermography which uses VIH to detect cracks, are all considered where relevant read-across can be found. Often being viscoelastic materials and composites with complex rheology, energetic materials subjected to vibrational loading tend to warm up, with potential for even greater temperature rises due to anisotropy-driven localised heating mechanisms. Binders soften as temperature rises, and the chance of damage increases, which may lead to runaway heating and thermal failure (if mechanical failure does not occur first).
\end{abstract}

Keywords Review $\cdot$ Energetic materials $\cdot$ Vibration $\cdot$ Vibration-induced heating (VIH) $\cdot$ Damage

\section{Introduction}

In this review we consider the mechanisms by which vibration-induced heating (VIH) of energetic materials might provide the conditions for unexpected ignition. As the vibrational self-heating of energetic materials is not a welldeveloped field (at least in the open literature), we include potentially useful insights from related fields and suggest possible future research, both experimental and modelling, which might help develop our understanding and hence reduce risk. The review is not intended to provide a full assessment of any particular modelling approach, nor to provide quantitative predictions for any given energetic material or application, but to outline the key themes and assess the underlying physics.

$\triangle$ J. I. Perry

jip24@cam.ac.uk

1 Cavendish Laboratory, University of Cambridge, J.J. Thomson Avenue, Cambridge CB3 0HE, UK
Energetic materials are subject to vibrational loading during transportation of all forms - the most intense situations likely experienced by weapons mounted on high-performance jets during take-off and landing. Where response is not entirely elastic, vibrational loading has the potential to result in VIH, meaning that there is a possible risk of such vibrations triggering an ignition event. In order to reduce this risk, qualification tests are undertaken in vibration facilities. The test spectra applied in such facilities are put together from a number of different types of vibration that the energetic material may be subjected to in service. In accelerated aging tests, the vibration amplitude is increased significantly above that expected in a realistic scenario. However, increasing the amplitude raises the probability of VIH. Since such critical test facilities are in high demand, the loss of such a facility due to ignition of an explosive device would have a significant impact on the ability of a country to qualify systems for service in a timely manner.

In addition to the direct benefit of reducing the risk to existing test facilities, an increased understanding of VIH in energetic materials will have other benefits. For example, 
if VIH is well understood and hence can be predicted, then testing programmes could be shortened in length by increasing the vibration amplitudes. Furthermore, improved understanding could result in test programmes that are more realistic, better energetic formulations and platform architectures, and smarter through-life monitoring and assessment of both munitions and energetic materials used in commercial applications.

VIH may lead to a variety of problematic scenarios for energetic systems. Cyclic mechanical loading and associated heating can result in accumulation of damage and other forms of degradation, which reduce service life. In some circumstances there may be a risk that such degradation could lead to a catastrophic ignition event, though in many cases the loss of mechanical integrity would necessitate remedial action before the risk of ignition is manifest. The physics of ignition of energetic materials is complex and varied, but the two most relevant categories to consider here are 'hot spots' and 'cook off'. Hot spots are the most widely accepted explanation for initiation of energetic materials under dynamic loading by a single loading pulse [1, 2]. Hot spots are micron-sized volumes within the material which experience temperatures that are hundreds (perhaps even thousands) of degrees higher than the bulk, for times that are typically less than a millisecond. They form due to non-uniformities within the material, and may involve processes such as frictional heating at interfaces, collapse of small voids, or highly localised plastic deformation associated with the propagation of cracks. Concerning cook-off, it has been found that if an energetic material is held at a modest raised temperature for an extended period of time, then ignition can occur [3]. The relationship between temperature and time-to-detonation has been characterised for a number of materials [4], but the mechanisms are still poorly understood. However, they are likely to involve coupling between thermal and mechanical behaviour rather than a single ignition site [5].

Under cyclic vibration, a third possible hybrid mechanism may exist, since high frequency vibrational loading can gradually heat a localised volume whose time- and volume scales are between those of hot spots and cook off. Such conditions have been achieved in small laboratory specimens [6].

The key message to absorb from this literature review is that timescales are central to the vibrational heating problem. The extreme local conditions required for ignition by hot spots can only be sustained briefly, so if the hot-spot relaxation time is significantly shorter than the time for one loading oscillation, the formation of a hot spot could still be considered to be due to a single loading pulse. If this is true, then in future modelling, the long-term, bulk (viscoelastic) heating and damage evolution could be separated out from short timescale, discrete hot-spot events.
There are two main mechanisms by which vibrational energy may be dissipated in an energetic material:

- Bulk heating: Nearly all energetic formulations are viscoelastic materials. This means they exhibit mechanical hysteresis so that when they are subjected to cyclic loading, they do not relax along the same load-deformation path they were loaded along. Accordingly, some of the mechanical work used to deform the material is dissipated as heat energy, raising the temperature.

- Interface heating: Many energetic materials have an internal granular structure, being composites with at least two separate phases having different mechanical properties. These can range from polymer-bonded explosives (PBXs) to propellants containing refractory particles. Internal interfaces are associated with a variety of energy dissipation mechanisms, and can also act as nuclei for crack formation and propagation, which generate heat [7]. Indeed, a technique known as Vibrothermography [8] makes use of these temperature rises to locate cracks. These processes can result in much greater local stresses than the applied bulk stress, and so very high local temperatures can be realised. Interfaces between energetic and casing may also be a source of heating, although likely less of a concern due to the higher thermal conductivity and low surface roughness of metal cases.

It should be noted that in some applications energetic materials are used in the form of loose powder or pellets. Vibration of granular media is particularly challenging to analyze, with densification, stratification, the 'Brazil nut effect' and other collective phenomena to consider. Friction between colliding particles can also lead to local heating [9]. However, the vibrational response of loose unbound grains is not well understood [10], and is outside the scope of this review.

For this review, we restricted ourselves primarily to the consideration of the mechanisms by which VIH, localised or bulk, might lead to the kind of conditions required to initiate cook-off or hot spots in energetic materials. Detailed consideration of the mechanisms by which such phenomena can subsequently result in detonation or deflagration have been widely published elsewhere, are not considered in much detail here. It quickly became clear that understanding the vibrational heating of bulk energetic materials requires that knowledge gained in several different areas of research to be combined. One aim of writing this review, therefore, was to discover where some of the issues raised by this problem may already have been partly answered.

In this review we consider the following topics: 
- The sensitivity of energetic materials: What conditions are required for a detonation or deflagration to be initiated? How does this depend on grain-scale properties?

- Viscoelastic heating: How can heat flow and viscoelastic deformation be coupled together in a model? What experimental methods can be employed to probe material properties?

- Composites: How does a material composed of a viscoelastic binder and stiffer inclusions behave? How does damage develop in such a system?

- Vibrothermography: Can we learn anything from the reverse approach of applying non-destructive vibration to investigate defects and damage?

- Vibrational heating of energetic materials: Finally, what directly relevant work has already been published? Section 2 begins with a discussion of early literature on the subject, and closes with a look at more recent research efforts.

The literature review is concluded by a discussion of possible ignition mechanisms arising from VIH of energetic materials, consideration is given to how such systems might be modelled, and what experiments could be developed to improve understanding of this phenomenon.

\section{Overview of Relevant Literature}

\section{Early Literature on Vibrational Heating of Energetics}

Interest in the response of energetic materials to vibrational loading first appears in the open literature in the early 1960 s as a result of the American manned spaceflight programme. Tormey and Britton [11] noted that the source of propulsive energy is an integral part of the total structure of a rocket, and so it is necessary to understand their mechanical properties in the environments to which they are subjected before (intentional) ignition. These include high-rate pressurisation,

Table 1 Estimates of service cyclic loading of solid propellants. A very early example from 1963 of 'vibration in flight' being noted as being of possible concern. Note that 'cps' refers to 'cycles per second'. From Ref. [11] reprinted by permission of the AmericanInstitute of Aeronautics and Astronautics, Inc.

\begin{tabular}{|c|c|c|}
\hline Service condition & Stain reversal frequency & $\begin{array}{l}\text { Possible total strain } \\
\text { reversals before } \\
\text { firing }\end{array}$ \\
\hline Vibration in flight & 100 to $500 \mathrm{cps}$ & $5 \times 10^{7}$ \\
\hline $\begin{array}{l}\text { Vibration during } \\
\text { ground transport }\end{array}$ & 10 to $500 \mathrm{cps}$ & $5 \times 10^{8}$ \\
\hline Temperature cycling & 1 per day & $2 \times 10^{3}$ \\
\hline Rotation in storage & 1 per month & $5 \times 10$ \\
\hline
\end{tabular}

acceleration and thermal cycling. Most notably, they specifically placed vibration in flight and vibration during ground transport at the top of the list of 'strain reversals' by both frequency and number (see Table 1). The experimental study they performed considered the effect of cyclic vibrational loading at different frequencies (with reference to the resonance response of the solid propellant of interest). Their discussions of VIH focussed on thermal degradation rather than ignition risk, and they noted that in (composite) propellants the effect of heating and heat flow are more complex than that for simpler polymers.

Tormey and Britton showed that vibration tends to soften or degrade the propellant mechanically, but that some of the degradation disappears during periods of rest. This point was also made by Schapery and Cantey in 1966 [12], who published a theoretical framework of the vibrational self-heating of solid propellants. While their analysis was primarily limited to dissipative viscoelastic heating, they noted that for cyclic loading, "it was necessary to account for degradation and to use a corrected loss tangent". This paper also includes a discussion of the effects of random loading (with a given spectral density) as distinct from steady-state harmonic oscillation. Schapery also published similar models for simple viscoelastic materials [13] and fibre composites [14].

The US Air Force was evidently keen to understand the dynamic response and failure mechanisms of solid propellants, as one report by Cantey from Lockheed in 1965 illustrates [15]. Here, the primary focus was on the fracture mechanics and risk of mechanical failure of solid propellants. Cantey designed various cyclic loading methods (such as shown in Fig. 1), and obtained some bulk material parameters, along with qualitative insight into some failure/ fracture phenomena. For example, he noted that mechanical failure generally occurred in the central (hottest) section of samples that were subjected to cyclic loading. Despite a relative lack of computational power or modern diagnostic techniques, it appears the level of understanding achieved in the 1960s was unsurpassed for some decades.

In the 1970s, Russian researchers [16] published what we believe to be the first discussion of initiation mechanisms resulting from vibrational as distinct from monotonic loading. The authors note that while single impacts produce ignition by strength failure and flow, friction and/or the presence of foreign refractory particles, vibrational loading has three distinct features:

- Cyclic recurrence (multiple 'load-unload' cycles)

- Much greater total duration than shock loading (a single cycle is has similarities to the shock produced by singleimpact loading)

- Intermittent loading changes the physico-mechanical properties and the type of specimen strain. 
Fig. 1 Schematic diagram of a constant shear-strain amplitude test device. From [12]

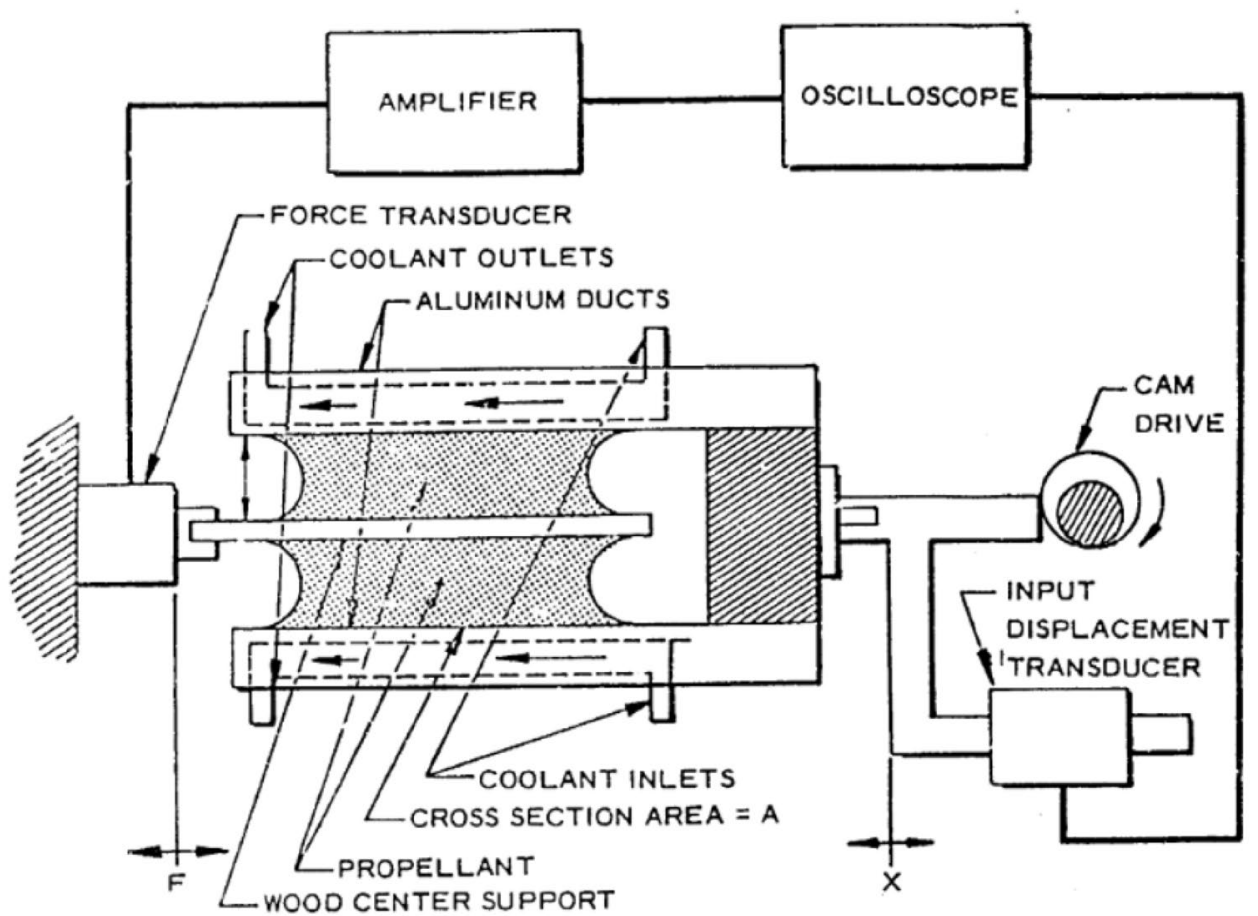

They claimed that temperature increases in vibrated explosives could result in thermal decomposition, and observed a transition from thermal decomposition to explosion under vibrational loading at $90{ }^{\circ} \mathrm{C}$ and $110 \mathrm{~Hz}$, with stresses of approximately $200 \mathrm{MPa}$, for hexogen (RDX)while "isothermal heating to the same temperature...does not change over to explosion". It is not clear what morphology (grain size, presence of plasticisers etc.) of RDX was used in the experiments. They argued that under vibrational loading the heating is non-uniform, resulting in some small volumes becoming much hotter than the bulk. Inelastic bulk deformation can also occur, because many loading cycles produce a rise in the bulk temperature resulting in a decrease in the ultimate tensile strength. Although more than four decades old, this paper remains perhaps the best report so far of how vibrational heating may lead to initiation via vibration-specific 'hybrid' bulk cook-off/localised hot-spot process.

In 1976 Hufferd \& Fitzgerald [17] reported the development of a solid propellant viscoelastic model for the Space Shuttle programme of the US National Aeronautics \& Space Administration (NASA). They built their model using power laws alone as they deemed temperature and frequency to be the only significant variables. Their approach was presented in some detail and with noteworthy clarity, though they made a number of assumptions such as simple Time-Temperature Superposition (TTS) relationships are valid, the effects of moisture can be ignored, and that the casing provides all the stiffness but none of the weight. Linear viscoelasticity was also assumed, though there was some discussion of more complex material behaviour-including the 'Kelvin effect', which is a second order effect of deformation in which some materials (highly filled polymers in particular) require a finite transverse force to maintain a simple shear geometry. Ageing was also noted as an issue, though it was not thoroughly investigated.

These early papers highlight a desire at the time to understand the mechanical properties of energetic materials, primarily in support of manned spaceflight. While the lack of computational power or modern diagnostic techniques limited their ability to probe the grain-scale physics, nevertheless these publications remained until recently some of the best efforts to understand the critical phenomena, and it is only in the last decade or so that significant further progress has been made. Before returning to consider recent studies on the vibrational heating of energetic materials, we will consider some topics the give insights into the problem: (i) the impact sensitivity of energetic materials, and (ii) the vibrational heating of viscoelastic polymers and composite structures.

\section{Sensitivity of Energetics}

The published literature on the mechanisms that govern the impact sensitivity of energetic solids has a history going back to the 1930s [18-20]. As this literature has been recently reviewed elsewhere [21, 22], we will concentrate in this review on publications that shed light on how changes in grain-scale morphology (and associated damage) produced 
by vibrational loading might affect the conditions required for ignition to occur.

Early attempts to understand the relationship between material/structural properties and sensitivity of energetic solids were limited to measurements of bulk material properties. For example, Matuszak et al. found a relationship between sensitivity and both the dynamic shear modulus and glass transition temperate in a PBX [23]. They achieved this using low frequency $(1-4 \mathrm{~Hz})$ deformation information obtained with a dynamic mechanical spectrometer and the skid-test drop height. It is of course important to note that different methods for testing the sensitivity of materials subjected to various loading conditions, which could produce different responses.

Damage accumulation during production or service usually degrades an energetic material's mechanical properties, and may lead to increased sensitivity. Rao noted that the propagation of cracks in propellants has been of concern for some time, not primarily because of an increase in the risk of ignition, but because cracks can lead to a non-uniform burn rate [24]. By considering the fracture of solid rocket propellant grains, Rao presented a method for computing the crack tip stress intensity factor and crack growth rate, and pointed out the importance of bonding between grains and binder with regard to predicting material response. This matter was subsequently studied in some considerable detail for the quasi-static deformation of PBXs using optical techniques, improving understanding of the relationships between crack growth, deformation, mechanical failure and sensitivity [25-27].

In the past decade, the focus has moved towards understanding the meso- and microstructural phenomena controlling ignition. However, as Welle et al. pointed out as recently as 2014 [28], all commonly used ignition and growth models only consider bulk powder metrics, and fail to explicitly include microstructural characteristics in ignition models despite a demonstrated (though not well understood) empirical link between morphology and initiation. Efforts to better understand hot-spot initiation continue, such as finite element modelling of pore collapse [29], assessment of various reaction kinetics models [30], and most recently application of Molecular Dynamics [31] (to give three examples from many). Horie [32] expanded the discussion of hot spot phenomena to include not only the classic mechanisms of adiabatic compression of trapped gas, friction, fracture and viscous heating but also more recently proposed possibilities such as plastic void collapse, shear banding, jetting, and heating at dislocation pile-ups. Horie pointed out that for materials with complex, variable heterogeneous microstructures, where history and environment may affect the dynamic response, it is unlikely that the relative importance of the different possible mechanisms will be the same for all loading conditions. It is, therefore, not surprising that there is still no agreement about the mechanisms by which energy is localised.

Although vibrational heating is more complicated, hotspot theory suggests that ignition is more likely to occur due to the concentration of thermal energy in a small volume rather than as a result of uniform heating. Furthermore, even though many energetic materials have a low thermal conductivity, the postulated high temperature and small size of hot spots indicate that, unless they cause ignition, they will disappear (or quench) within a very short time. This is a critical point to emphasise, since unless the time for one loading cycle is similar in duration to the hot spot quench time, critical hot spots would need to form during a single loading cycle rather than developing over many oscillations. Accordingly, predictive modelling of reactive behaviour needs to consider many orders of time and length scales, as Fig. 2 illustrates.

With the knowledge that it is localised events, arising from non-uniformity in materials, which drive reactive behaviour, several authors have attempted to model ignition probability. Kim et al. [33] took an approach based on statistical analysis, assessing the relative importance of two sources of stochasticity: (i) random variations in microstructure, and (ii) random fluctuations in grain-binder interfacial bonding strength. Barua \& Zhou used a more direct approach, namely a Lagrangian finite element method to make predictions (Fig. 3) about the microstructural response of PBX to shock loading (strain rates of $10^{4}-10^{5} \mathrm{~s}^{-1}$ ) [34]. Their model attempted to take account of grain-scale effects during deformation such as microcracking (in both bulk constituents and along grain/matrix interfaces), frictional heating and thermomechanical coupling-and included strain rate sensitivity, strain hardening and temperature dependence.

Most models tend to focus only on the viscoelasticity of the binder, assuming the granular phase is either rigid or elastic. Hardin and Zhou [35] examined this assumption by means of a theoretical study that treated HMX crystals in a PBX as either elastic or viscoplastic. Their results suggest that if the crystals are elastic, they would have a lower impact ignition threshold. Since in reality HMX crystals do not come in two mechanically distinct forms, it is not possible to make a direct comparison with experimental data. However, their study does illustrate a need to carefully consider all the phases of a mixtures model since assumptions made about the deformation of grains, even if they may be thought to be a second order issue, may result in wrong estimates of some important parameters such as the amount of frictional heating. Duarte et al. [36] considered a simplified system consisting of a single particle embedded in a polymeric matrix and attempted to predict how pre-existing damage might affect hot spot nucleation. The authors confirmed that increased damage is likely to raise the probability of hot 


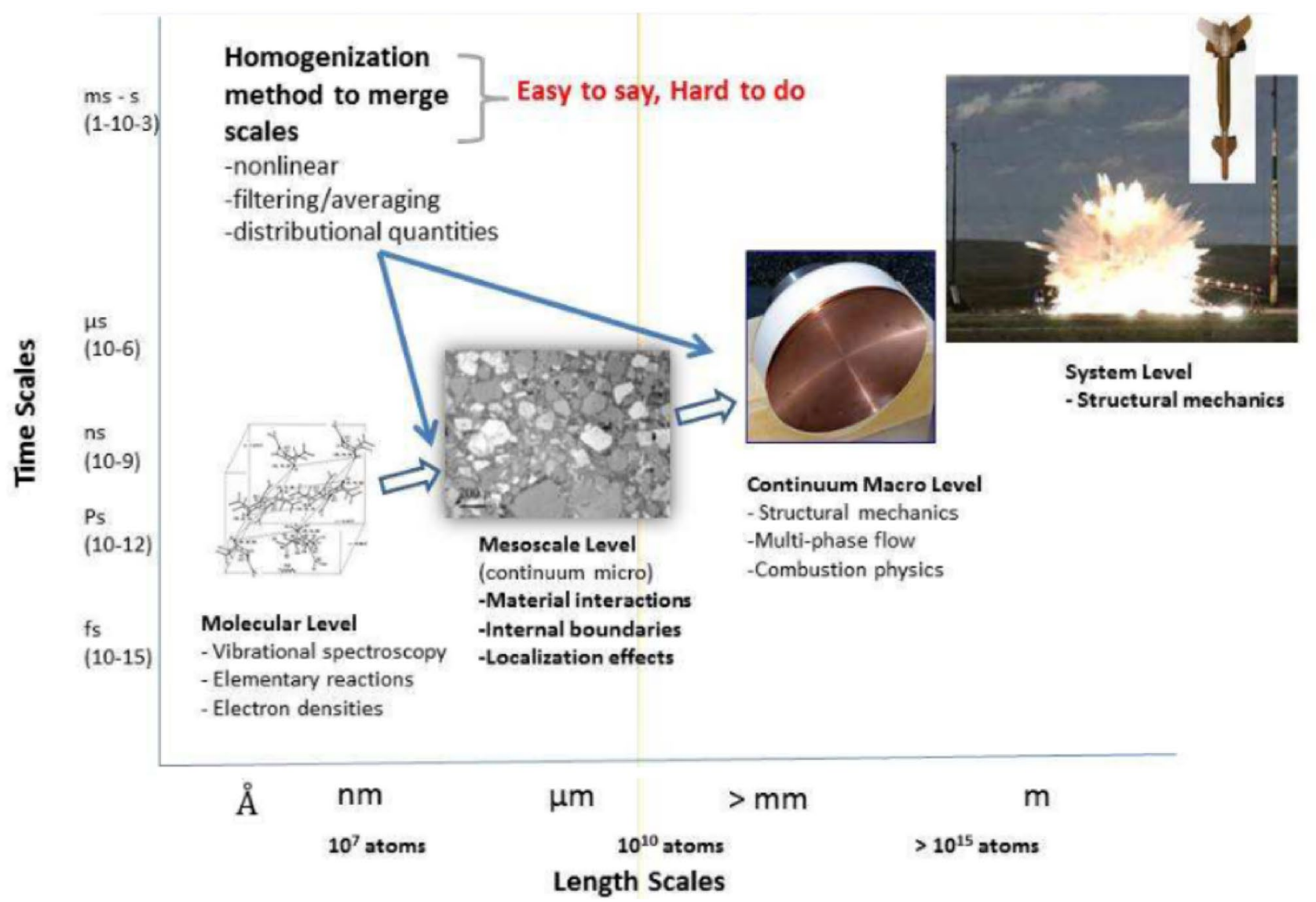

Fig. 2 Multiscale modelling and simulation for explosives reactive behaviour. Reproduced from [32] with kind permission of Trans Tech Publications

spots leading to ignition, and determined that frictional heating, particularly at cracks that intersect the crystal-binder interface, was the main cause.

Cyclic loading in the form of dynamic mechanical analysis (DMA) has been applied to propellants [37-42] in order to better understand their mechanical properties under a variety of loading conditions and aging scenarios. Although DMA testing involves heating samples to a known temperature rather than allowing self-heating, its ability to test materials over a range of temperatures and frequencies could provide a controlled method for extracting properties of interest without resorting to time-temperature superposition assumptions.

Several authors have considered how in-service diagnostic methods could be used to monitor damage occurring within a rocket [43], the Space Shuttle's "Integrated Vehicle Health Management" project [44] being the most well-known example of this. Others have explored options for reducing sensitivity via changes to explosive compositions, such as the addition of low strength, lubricating, chemically stable phlegmatizers $[45,46]$, polymeric bonding agents which reduce the risk of damage at grain-binder interfaces [47], and even the use of graphene to reduce creep and increase viscoelastic storage modulus [48].

\section{Vibrational Heating of Viscoelastic Materials}

Although there are few papers about the vibrational heating of energetic materials, there are a large number of publications on the self-heating of inert viscoelastic materials. It is worth considering this body of work for the approaches taken to experimental design and modelling. Further, some of the papers, although ostensibly about inert materials, discuss applications to energetics.

The idea of employing time-temperature superposition for the prediction of polymer deformation behaviour may be traced back to the classic paper by Williams et al. [49] and the ensuing concept of the WLF transform. Regarding cyclic loading (and self-heating in particular), Schapery provided an early theoretical approach [50]. As well as considering a generic polymer, he also discussed propellants, notably with respect to the possibility of 'thermal instability' when the shear stress exceeds a critical value. 
Fig. 3 Evolution of equivalent stress and temperature in PBX under shock loading. Samples are compressed vertically (in the image) at $50 \mathrm{~m} \mathrm{~s}^{-1}$ (a strain rate of almost $\left.17,000 \mathrm{~s}^{-1}\right)$.

Taken from [34]
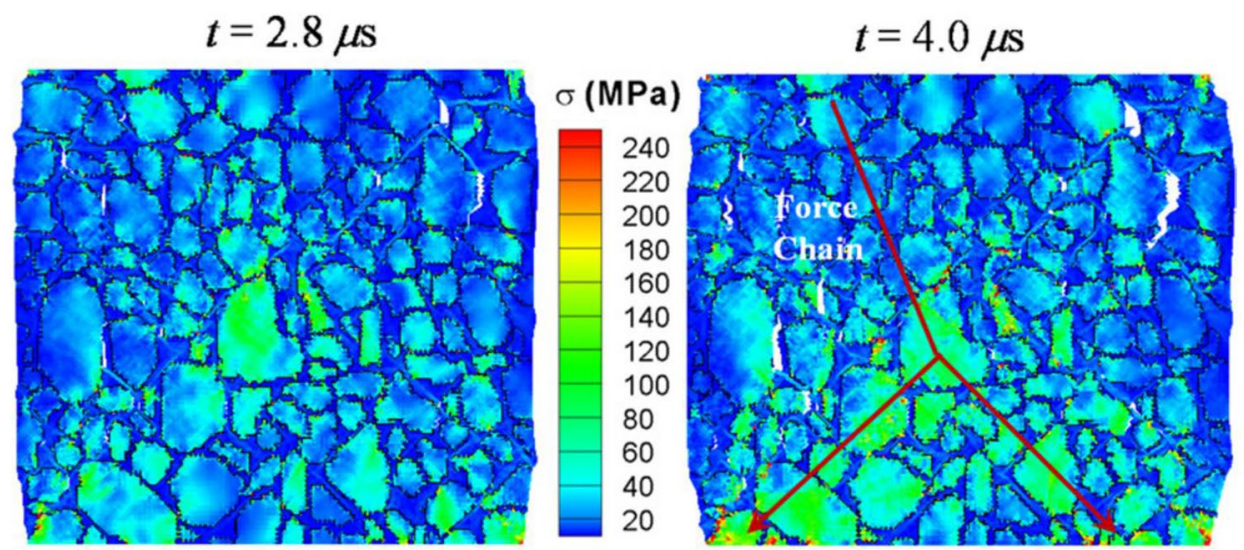

(a) Distribution of equivalent stress
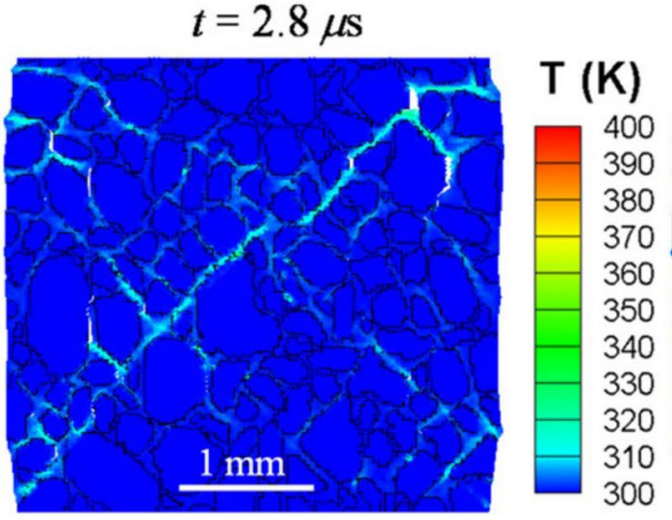

$t=4.0 \mu \mathrm{s}$

(b) Distribution of temperature

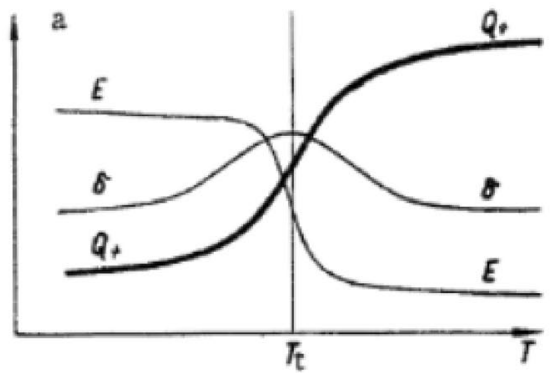

(a)

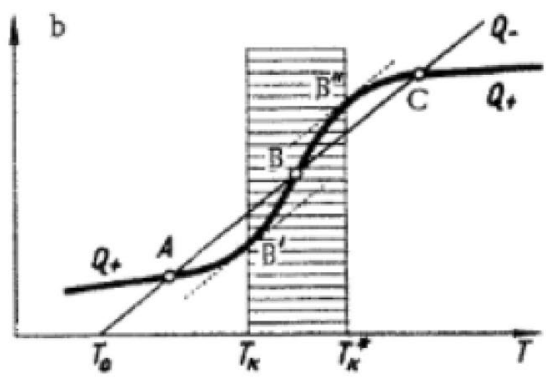

(b)

between these two, around the transition temperature, is a region where a steady-state solution is not possible (point B being an unstable equilibrium). $T_{k}$ and $T_{k}^{*}$ are the thresholds on heating and cooling respectively where the polymer will abruptly shift from one regime to the other. From [51]

mechanical failure, or to a high temperature equilibrium state which does not usually last very long before thermal failure occurs. Figure 4 illustrates how the switch from one to the other occurs around the softening (or 'glass transition') temperature of a polymer $\left(T_{t}\right)$, when the loss angle $\delta$ is at a maximum and the modulus $E$ is decreasing. Around 
the same time, Schapery stated that "a large temperature rise may occur when the applied stress amplitude is above a certain critical value which depends on thermal and mechanical properties, geometry, and frequency" [13].

Several other papers from the 1960s and "70s provide further insight. For example, Knauss developed a theoretical framework for time-dependent failure of viscoelastic materials (including propellants) under cyclic loading, with consideration given to strain and frequency-dependent behaviour [53]. Savkin et al. investigated the effect of supramolecular polymer structures on the self-heating of polymers under cyclic loading [54]. They found that a coarser, more varied structure led to more heating. Other researchers looked at the effect of simple shapes on viscoelastic heating including spheres [55] and spherical cavities [56]. Karnaukhov et al. [57] pointed out that that since many viscoelastic materials combine low thermal conductivity, high energy dissipation and markedly temperature-dependent properties there is a risk of 'thermal catastrophe' if they are subjected to cyclic loading.

Since then the focus of research into the viscoelastic heating of polymers has been into: (i) improving the temporal and spatial resolutions of diagnostic techniques such as infrared cameras [58]); (ii) the assessment of materials with complex nonlinear rheological behaviour [59, 60]; and (iii) increasingly sophisticated finite element (FE) modelling [61]. However, despite the fact that numerical models are widely used, there have been some recent analytical studies of particular geometries [62]. As de Cazenove noted, however, only a very small fraction of research into viscoelasticity considers self-heating [63], despite the importance of temperature to the mechanical properties of polymers.

Degradation and eventual failure due to repeated loading producing accumulation of damage is less commonly considered in polymers. A creep-like response where strains gradually increase with time is often proposed, and it has been noted that viscoelastic heating during cyclic loading experiments may occur, making it difficult to decouple the effects of thermal and mechanical degradation [64]. Krairi and Doghri's constitutive model for thermoplastic polymers coupled viscoelasticity, viscoplasticity and ductile damage [65], while Shojaei \& Volgers [66] presented "a fully coupled elastic, plastic, thermal and fatigue damage computational tool for unfilled polymers to investigate the role of self-heating in lifetime prognoses". Other complications such as the effect of humidity are almost always overlooked or ignored [67].

\section{Vibrational Heating of Inert Composites}

The energetic materials that are being considered in this review are primarily composites consisting of a polymer binder filled with crystals that are harder than the matrix.
Since far more research into vibrational damage of inert composites has been performed than on energetics, it is sensible to consider whether the insights obtained for inert materials can be applied to energetic ones. Fibre composites have been more extensively studied than granular, but the development of damage is a major topic of interest in both.

The deformation of fibre-reinforced polymer composites proceeds by localised damage-matrix cracking, delamination, fibre-pull out and a number of other mechanismswhich often results in a gradual reduction in strength prior to catastrophic failure. The fatigue of structural composites (which are usually fibre-reinforced polymers) has been a matter of concern since the late 1960s [68, 69]. While a full description of this is beyond the scope of this review, these (largely inelastic) deformation and damage modes can contribute to $\mathrm{VIH}$, and so provide insights valid for energetic composites.

The development of a coupled deformation and heat flow model for a composite is intrinsically more difficult than for a single-phase material, and attempts to do this have only made progress this century. Progressing iteratively from 'simple' viscoelastic materials, some studies considered the effect of specific defects [70] or stress concentrators [71] while other studied considered simplified 'composites' containing a single inclusion [72, 73]. Khan and Muliana presented a "fully coupled heat conduction and deformation analysis" of both viscoelastic polymers [74] and particlereinforced polymer composites [75, 76], improving on previous models by including nonlinear viscoelastic behaviour. They also argued that the addition of elastic particles can reduce heat build-up by increasing thermal conductivity, although this must be balanced against the potential for additional energy absorption [77] (and heat generation) associated with interfaces.

Several continuum-based attempts have been made at modelling damage and heating in composites. For example, Drozdov modelled viscoelastoplasticity and the lowcycle fatigue of polyamide- 6 reinforced with short glass fibres [78]. His model, based on polymer chain dynamics, "takes into account damage accumulation, but describes it as changes in the energy of interaction between chains in a polymer network, not as changes in elastic energy stored in individual chains." Nevertheless, he still treated damage as a simple parameter, without explicitly considering specific mechanisms such as chain breakage in the semicrystalline polymer and breaking and debonding of fibres. Meneghetti and Quaresimin [79] developed a novel approach for estimating fatigue strength and damage evolution experimentally, by measuring heat dissipation in a notched fibre-reinforced composite specimen that was subjected to cyclic loading. After accounting for the heat generated by viscoelastic bulk heating, they attributed any additional heat to be due to the accumulation of damage. While their approach seems 
sensible, caution is required as it relies on being able to calculate (a) viscoelastic effects very accurately and reliably, particularly the temperature dependence, and (b) the decoupling of heat generated due to the formation of new cracks/ debonding and that generated subsequently as the cracks are subjected to continued cyclic loading.

Eftekhari and Fatemi investigated whether the number of cycles needed for failure of polymers and composites depends on the frequency of loading [80]. They found there is a balance between the greater proportion of energy absorbed by viscoelastic damping at low frequencies and an increased rate of energy input at high frequencies that leads to self-heating and softening at higher rate. Somewhere between the two frequency regimes (typically at frequencies around $10 \mathrm{~Hz}$ ), the specimens have the best chance of survival. Mortazavian and Fatemi also showed that selfheating (and associated reduction in strength) is an important consideration when testing fatigue of fibre composites, alongside other environmental factors such as moisture [81].

Recently a number of authors have provided an updated account of the 'thermal instability' argument first proposed in the 1960s [50, 51]. For example, Katunin and Fidali studied the self-heating of polymeric laminated composite plates under resonant vibrations [82]. They showed that selfheating initially tends towards a steady state temperature where viscoelastic heat generation and thermal dissipation balance, but this state of affairs is eventually followed by an unstable third phase where the rate of damage accumulation accelerates, causing thermal runaway and breakdown (see Fig. 5). The third phase is catastrophic, unstable and short in duration, with no obvious way of predicting when it will occur. Note this may not hold for all materials.

These observations on an inert polymer composite raise two points of interest with respect to vibrational heating of energetics. First, the constant equilibrium temperature in the second (stable) phase implies that additional heating due to damage is either negligible or can be estimated based on a slow rate of temperature increase. Second, the risks associated with VIH for a particular material are likely to depend on whether the plateau temperature and damage experienced during the second phase are sufficient to cause cook-off ignition.

In 2017, Katunin et al. [83] noted that specimen anisotropy could result in highly localised stress, heating and damage-i.e. a hot spot—resulting in a much more rapid transition to thermal failure than might be predicted given the bulk material response. It is also possible, of course, that mechanical failure may occur before the third phase is reached. They proposed acoustic emission measurements as a means of directly monitoring damage accumulation [84, 85].

Several other methods for in-situ measurement of damage have been attempted. Naderi \& Khonsari also observed a three-phase thermomechanical response, although the third phase was less acute [86]. They employed infrared cameras to measure temperature rise during DMA testing of a glass/epoxy woven composite at $10 \mathrm{~Hz}$. Magi et al. [87] studied damage initiation and structural degradation through resonance vibration, using observed changes in temperature as a means of estimating damage within a simplified composite material (Fig. 6).

\section{Vibrothermography}

Vibrothermography involves applying sufficiently powerful ultrasonic vibrations to a structure so that cracks, delaminations and other non-uniformities will be heated preferentially to the bulk. While the energies and temperatures involved are small, key to the technique is an understanding of vibrational heating of small-scale features and damage, which is a central theme of this review.
Fig. 5 Thermal failure observed in a polymer composite. From [82]

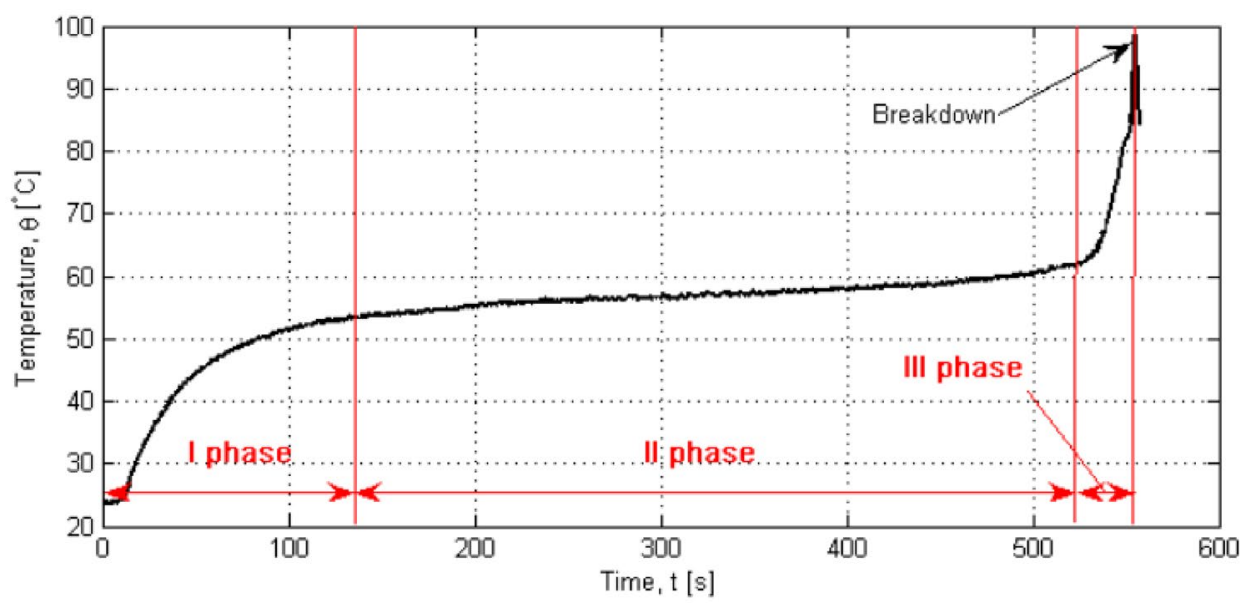




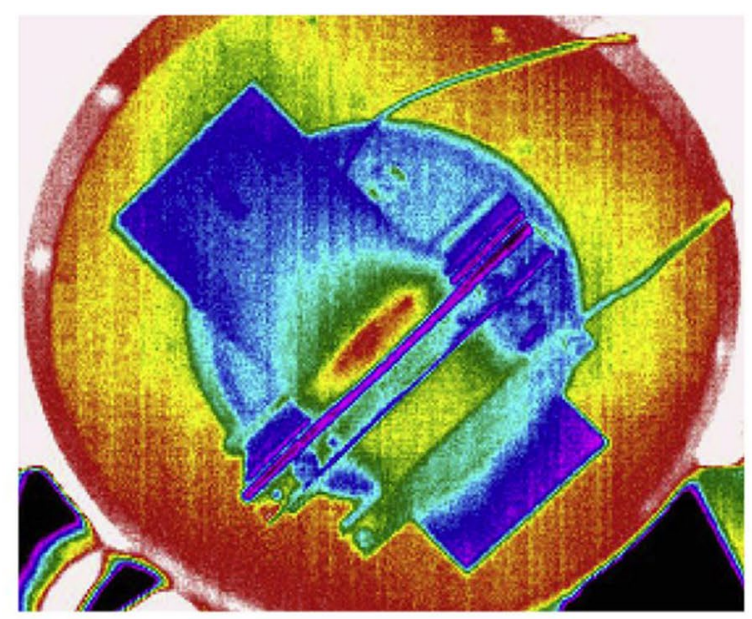

(a)

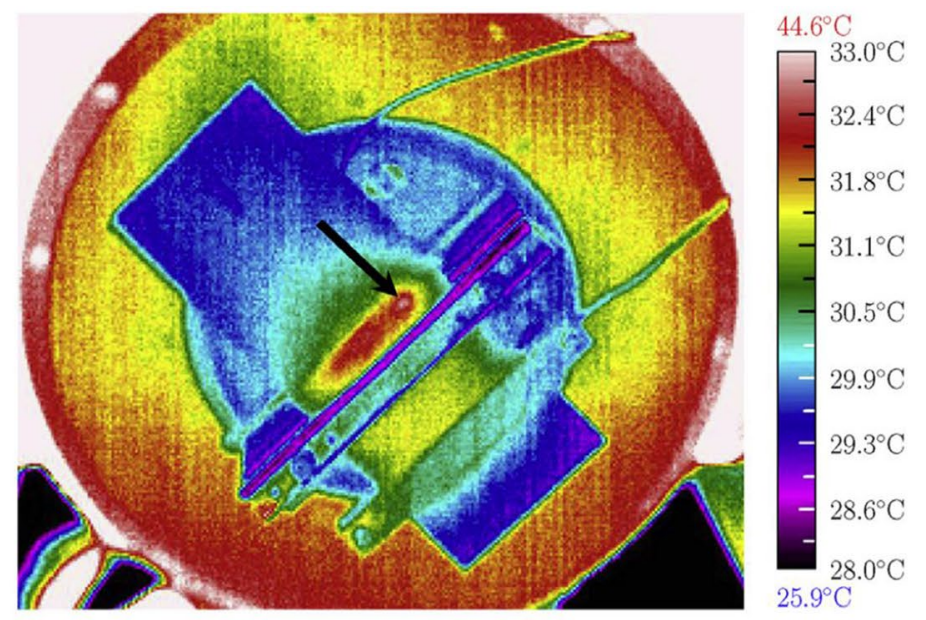

(b)
Fig. 6 Thermal images of the top surface of a thin rectangular specimen (a) before and (b) after the critical event. The long axis of the coupon runs top-left to bottom-right in the images; it is held by means of twin clamping rods running normal to this axis along its middle. Oscillatory loading is applied by means of a vibrating table and a weight clamped to the specimen some distance away fromand running parallel to- the clamping rods (towards the bottom right in the images). Delamination is indicated by the arrow. From [87]
In 2011, Renshaw et al. wrote an introduction to vibrothermography in which they outlined the sources of heat generation [8]. They pointed out that there was still a lack of understanding of the physics of the heat generation process, but they did distinguish three distinct heating mechanisms and claimed that "spatially isolating regions of heat generation provides a means to determine contributions from different heat-generating mechanisms on the total heat generation of the indication." The three mechanisms they identified are:

- Friction: In cracks, frictional heat generation occurs due to rubbing of contacting points (asperities). Rubbing may also produce plastic deformation.

- Viscoelasticity: In addition to bulk viscoelastic heating, significant localized heating can occur in regions of stress concentration around a defect. It is usually possible to distinguish between the two (see Fig. 7).

- Plasticity: Heating due to plasticity, associated with crack propagation and material degradation, only begins to occur above a threshold stress and in specific locations. This is in contrast with viscoelasticity, which is linearly related to the vibrational stress level at all points throughout a structure, and so experiments in which comparisons are made using different vibrational inputs can help distinguish between the two.

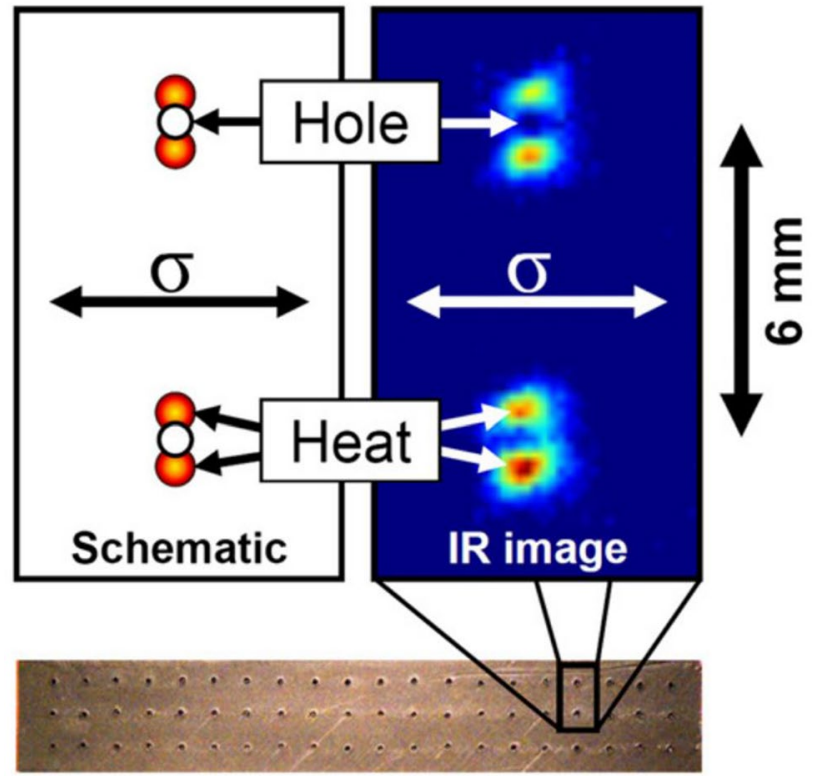

CFRP bar with drilled holes

Fig. 7 Bottom: a carbon-fibre-reinforced polymer (CFRP) sample containing an array of drilled holes. Top left: schematic of a CFRP sample containing drilled holes with arrows showing the direction of applied stress. Top right: observed infrared heating in the bar due to viscoelasticity and the stress concentration at the holes after $1.0 \mathrm{~s}$ of excitation. The authors did not provide a temperature scale bar. From [8] 
Montesano et al. used vibrothermography to investigate the fatigue behaviour of a carbon fibre reinforced polymer composite [88]. They used an infrared camera to record the initiation of matrix deformation and cracking within specimens. Their results were in good agreement with those obtained using an extensometer. Despite vibrothermography being originally intended as a low-intensity, non-destructive probe, it can clearly be used as a gentler alternative to more destructive testing techniques for the study of vibrational heating, and as an expanding area of research could continue to provide useful insight into the physics of VIH.

\section{Vibrational Heating of Energetic Materials}

Apart from those papers on polymers and polymer composites which refer more or less opaquely to energetic applications, little was published on the topic of vibrational heating of energetic materials between the late 1970s and around a decade ago. One exception to this was Loginov and colleagues, who followed their early work (discussed earlier) with a number of papers on this topic between 1976 and 2009 [16, 45, 89-97].

In his 1997 paper, Loginov outlined the structural and physicochemical changes that take place in RDX under vibration [95]. By measuring the microstructural changes that took place using X-ray diffraction, X-ray phase analysis and microscopy (plus IR spectroscopy for chemical analysis), he argued that the decomposition that takes place under vibration can be quite different to simple thermal decomposition. He used a simple and novel experimental procedure in which the entire experiment was enclosed in a pressure chamber, allowing decomposition to be monitored via changes in pressure. Loginov concluded that vibrationinduced damage can make ignition more likely, and even suggested an atomic-scale mechanism:

Thus, the accelerated decomposition of RDX under vibration is affected by structural and physicochemical changes in RDX crystals and molecules. Vibration accelerates the formation of crystal defects, the progress of inelastic deformation, fracture, and dispersion, and the formation of activated molecules on 'fresh' fracture surfaces of particles. Vibration can change the configuration plane of the node at the amine nitrogen atom, and hence it leads to a shift of the absorption bands of the nitramine groups in the IR spectrum of RDX.

Loginov also highlighted that while under some circumstances cyclic loading can result in progressively increasing temperatures, at moderate rates it is possible (in lead azide) for the unloading cycle to prevent decomposition reaction by reducing the temperature of local hot spots, compared with equivalent single-impact loading [97].

The complexity of composites means that testing methods and specimen design must be carefully considered. Wani et al. cautioned that testing parameters (heating rate, frequency, stress/strain applied, temperature etc.) affect the measured mechanical response in composite propellants [98]. They published an "exhaustive data set" using DMA testing that included multi-strain and multi-frequency strain sweeps, stress relaxation and creep tests. Although they did not consider either self-heating due to vibration or grainscale mechanisms, their methodology may be useful for building macroscale material models of propellants. Further, since there is a size dependence to their mechanical properties [99-102], composites cannot be considered as being just another material. This means that, unlike for simpler materials such as metals and polymers, a composite specimen can never be truly representative of the bulk, and so tests on composites unavoidably involve structural analysis rather than just material characterisation. Composites are, if you like, intermediate between materials and structures.

Damage and ageing in energetic materials (and their effects on sensitivity) have been widely considered in the literature, but have not often been considered in connection with VIH. One exception where the combined risks of damage and vibrational loading was considered was in Yilmaz's thesis [103], where a simple parameter damage model was considered alongside the expected loading history to assess the risks associated with safe transport of energetic materials.

Shou et al. combined modelling and experiment to study the oscillatory loading of a particulate composite, including self-heating to a steady-state temperature [104]. The materials they investigated were inert, though the paper they wrote on their research (which was funded by the US Air Force) made direct reference to military applications. The authors' research is a noteworthy study into modelling the self-heating of particulate composites, although a low granular fill fraction minimised grain-grain contact so that viscoelastic heating dominated, and damage accumulation was not considered.

Researchers at Purdue University studied the vibrational heating of energetic materials, their stated interest being in facilitating remote detection by generating detectable vapours via acoustic excitation $\}$. The frequency response [105] and (very small) temperature increases [106] were recorded, with both broadband and single-frequency oscillatory loading conditions being studied, and a continuum model used to simulate deformation and heat flow [107]. Their focus was the study of bulk response, and their results showed (as expected) greater temperature increases for materials with higher loss moduli, but they also noticed that both the presence of cracks and higher crystal volume ratios 
Fig. 8 Left: Photograph of a specimen containing five ammonium perchlorate particles that were dyed in order to increase visual contrast. Right: Infrared thermal images showing the temperature field of the surface of the specimen $(10 \mathrm{~W}$ of supplied electrical power, $2 \mathrm{~s}$ of excitation at $210 \mathrm{kHz}$ ). From [6]
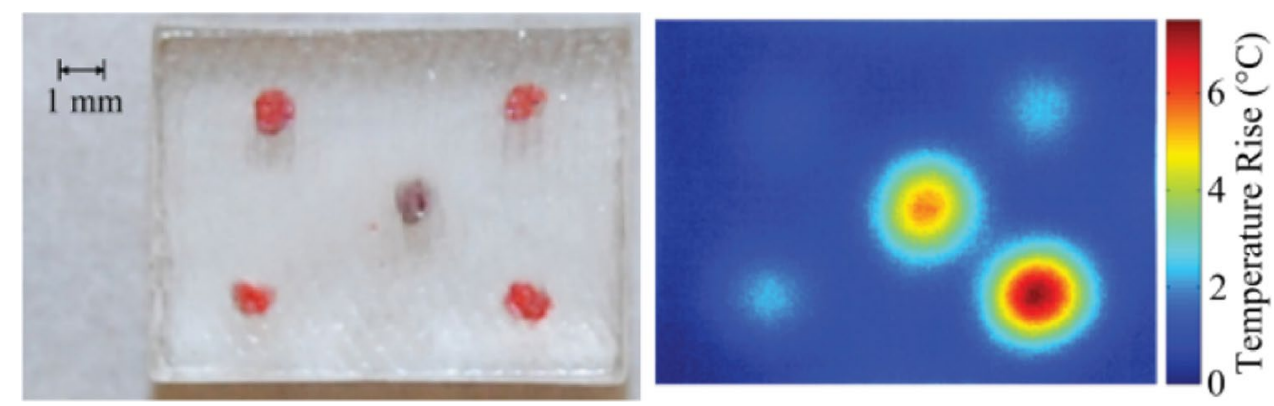

led to significant stress concentrations and associated localised heating.

Another set of publications from Purdue focussed on more intense vibrational heating, intended to probe the physics of hot-spot ignition. Mares et al. began by studying PBX 9501, finding frequency dependent heating processes such as a shift from bulk motion to particle-scale processes at higher frequencies, and observing temperature spikes at particular resonant frequencies [108]. However, IR cameras were not capable of capturing grain-scale events, and the researchers shifted to studying simplified samples containing just a few 'representative' inclusions. By coupling $210 \mathrm{kHz}$ piezotransducers to an elastic binder specimen containing five discrete energetic particles (Fig. 8 left) so as to eliminate viscoelastic bulk heating and isolate grain interface processes, the IR video they took captured localised heating around the grains (Fig. 8 right), which continued up to the point of ignition. A subsequent paper [109] noted that less spherical particles produced greater heat generation, and that localised heating may also arise from a 'focussed-viscoelastic' effect, and/or frictional heating of interfaces.

Roberts et al. presented an interesting method for determining the temperature rise in HMX [110]. The technique is based on the fact that HMX undergoes a thermally-induced phase transition at $c a .170{ }^{\circ} \mathrm{C}$, which can be detected by the frequency doubling of incident laser radiation [111], a phenomenon which can be used as a temperature sensor. A subsequent paper from the same authors [112] showed that both proximity of several grains within a binder, and poor crystal-binder adhesion, increases the extent of localised heating. Alongside the experimental work, the Purdue researchers recently published two single-crystal-in-binder modelling studies, one focussing on fracture [113] and the other on hot spots [114].

At the University of Illinois, You et al. applied $20 \mathrm{kHz}$ vibration via a piezo-transducer to a polydimethylsiloxane (PDMS) sample containing two sucrose crystals, one of which was coated in a thin film of polyethylene glycol to simulate grain-binder delamination [115]. They showed that locally temperature rises of hundreds of degrees can occur in the coated crystal, as Fig. 9 illustrates, with no heating in the uncoated crystal.

\section{Discussion}

At the macro-scale, models that combine cyclic deformation with heat flow are being developed for both unfilled viscoelastic polymers and particulate-loaded polymer composites. Experimental efforts have combined DMA (or similar vibration-inducing apparatus) with an increasing number of diagnostics in order to test these theories. However, analysis of grain-scale damage mechanisms is still in its infancy, with several research groups publishing studies on simplified composite/energetic specimens vibrated at near- $\mathrm{MHz}$ frequencies using piezo-transducers. Almost none of the (a)

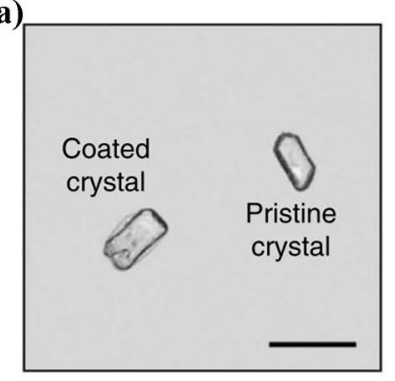

(b)

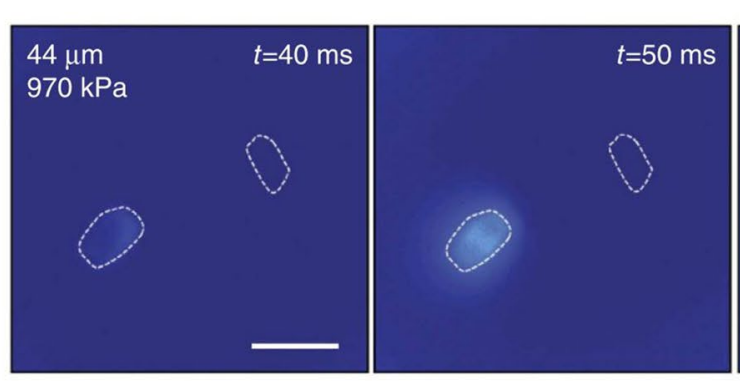

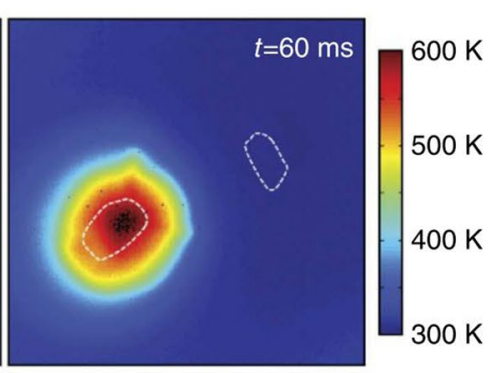

Fig. 9 Hot spot generation from surface-coated inclusions. a Optical micrograph of a composite of two sucrose crystals (one PEG-coated) embedded in PDMS and $\mathbf{b}$ thermographs of the sample during ultrasonic irradiation. All scale bars, $1 \mathrm{~mm}$. From [115] 
literature in this area has been performed with the stated purpose of predicting unexpected ignition from VIH, but rather the motivations include: through-life performance stability, remote sensing, development of novel (controlled) triggering methods, and better understanding of the physics of hot-spot ignition.

Viscoelastic materials subjected to cyclic loading increase in temperature, often reaching a steady thermal state, before either mechanical failure occurs or damage evolution results in runaway heating leading to thermal failure. Moderate heating (a few tens of degrees) is sufficient to significantly soften many binder materials, and so VIH in polymers is of concern in a variety of applications, though research is still lacking. In energetic materials, ignition is generally understood to initiate at localised hot spots, though the connection with VIH is not currently understood except for highly simplified systems.

Energetic materials are usually complex, inhomogeneous, composite systems. The most commonly discussed pathway to ignition is via the formation of hot spots, which are very high energy density events occurring in a small volume for a very short period of time. They arise via a number of mechanisms due to anisotropies within a material. Ignition may also occur when an energetic material is held at an elevated temperature for an extended period of time, and is known as 'cook-off'. The underlying mechanisms for this are even less well understood.

Under vibrational loading, so long as the 'relaxation' (or cooling) time of a potential hot spot is sufficiently short with respect to one cycle, we can separate long-term vibration (which results in viscoelastic heating and damage) from hot spot events. This is because although the chance of a hot spot occurring may increase due to the heating and damage, initiation itself must occur during a single loading half-cycle/'shock', since the unloading half-cycle provides sufficient time for the localised heat to dissipate into the bulk. Note that although the temperatures reached in hot spots are large, their contribution to bulk heating will be negligible due to the small amount of heat energy they contain.

However, this hypothesis does not hold in two cases. First, if catastrophic damage is occurring in the material then macroscopic heating due to that damage is not negligible compared with bulk viscoelastic heating. Second, at very high frequencies, it is possible that temperatures sufficient to cause ignition can be reached gradually yet locally quickly at interfaces due to localised phenomena such as frictional rubbing.

We therefore have identified three distinct cases which could result in ignition under oscillatory loading:

1. A one-off hot spot initiation due to a single loading 'pulse', which then follows a similar trajectory to shock loading of an energetic material (albeit at a lower threshold due to the warmed, vibration-damaged environment).

2. Cook-off ignition due to sustained raised temperature resulting from bulk viscoelastic heating (again, potentially with a lower threshold due to the material's loading history).

3. Vibration-assisted hot spot/cook-off hybrid ignition event, where very high frequency vibration causes frictional heating at a damaged interface within the material.

4. Another, unforeseen mechanical and/or chemical ignition mechanism enabled by a warmed, damaged, repeatedly stressed-and-strained environment.

Regardless of which scenario provides the credible threat, the required understanding of material properties is the same: We need to understand (a) the evolution of damage, (b) bulk heating due to viscoelastic behaviour, and (c) the relationship between damage and ignition sensitivity (either due to cook-off or single-loading-induced hot spot formation). Expected loading conditions in any real-world scenario must also be considered carefully, including resonances and stress focussing due to macro-scale geometries. As it is almost certainly not feasible to create a single model representative of an energetic system in its entirety, modelling approaches will have to separate long timescale, bulk behaviour from localised, transient events.

It should be noted that the risk of VIH involving energetic materials will strongly depend on specific circumstances, service environment, materials and geometries involved; this review is intended to highlight the relevant phenomena of interest, and intentionally offers no quantitative risk analysis with respect to any specific application.

Looking forward, future efforts to improve understanding of VIH of energetics (and the associated risks of unintended combustion events) align with wider research interests with regards to better understanding the properties of energetic materials. Degradation from repeated mechanical loading and/or heating is a concern even if in-service conditions are unlikely to ever lead to a significant risk of unexpected ignition. One would expect accelerated ageing tests on entire systems to remain a crucial safety validation step for some time, as the complex mix of materials, structures, phenomena and timescales makes accurate modelling large lengthand timescales very challenging. However, by combining small-scale experiments on simplified systems with a variety of computational and theoretical efforts, better predictive capability with regards to local/bulk heating, damage and subsequent risk of ignition may help reduce reliance on large-scale testing in future. 
Acknowledgements The authors would like to thank our colleagues D.M. Williamson, N.E. Taylor, L.J. Lea and C.H. Braithwaite for their insight and support with this work, and to QinetiQ Plc for funding the Cambridge QinetiQ Research Fellowship.

Open Access This article is licensed under a Creative Commons Attribution 4.0 International License, which permits use, sharing, adaptation, distribution and reproduction in any medium or format, as long as you give appropriate credit to the original author(s) and the source, provide a link to the Creative Commons licence, and indicate if changes were made. The images or other third party material in this article are included in the article's Creative Commons licence, unless indicated otherwise in a credit line to the material. If material is not included in the article's Creative Commons licence and your intended use is not permitted by statutory regulation or exceeds the permitted use, you will need to obtain permission directly from the copyright holder. To view a copy of this licence, visit http://creativecommons.org/licenses/by/4.0/.

\section{References}

1. Field JE (1992) Hot spot ignition mechanisms for explosives. Acc Chem Res 25:489-496

2. Mellor AM, Wiegand DA, Isom KB (1995) Hot spot histories in energetic materials. Combust Flame 101:26-35

3. Catalano E, McGuire R, Lee E, Wrenn E, Ornellas D, Walton J (1976) Thermal decomposition and reaction of confined explosives. United States, Report no. UCRL-78245

4. Dobratz BM (1981) LLNL explosives handbook: properties of chemical explosives and explosives and explosive simulants. Lawrence Livermore National Lab., CA (USA), Report no. UCRL-52997 United States NTIS, PC A23/MF A01. LLNL English

5. Dickson PM, Asay BW, Henson BF, Smilowitz LB (2004) Thermal cook-off response of confined PBX 9501. Proc R Soc Lond A 460:3447-3455

6. Mares JO, Miller JK, Gunduz IE, Rhoads JF, Son SF (2014) Heat generation in an elastic binder system with embedded discrete energetic particles due to high-frequency, periodic mechanical excitation. J Appl Phys 116:204-902

7. Holmes W, Francis RS, Fayer MD (1999) Crack propagation induced heating in crystalline energetic materials. J Chem Phys 110:3576-3583

8. Renshaw J, Chen JC, Holland SD, Thompson RB (2011) The sources of heat generation in vibrothermography. NDT E Int 44:736-739

9. Das P, Puri S, Schwartz M (2018) Granular fluids with solid friction and heating. Granular Matter 20:15

10. Golovanevskiy VA, Arsentyev VA, Blekhman II, Vasilkov VB, Azbel YI, Yakimova KS (2011) Vibration-induced phenomena in bulk granular materials. Int J Miner Process 100:79-85

11. Tormey JF, Britton SC (1963) Effect of cyclic loading on solid propellant grain structures. AIAA J 1:1763-1770

12. Schapery RA, Cantey DE (1966) Thermomechanical response studies of solid propellants subjected to cyclic and random loading. AIAA J 4:255

13. Schapery RA (1965) Thermomechanical behavior of viscoelastic media with variable properties subjected to cyclic loading. J Appl Mech 32:611-619

14. Schapery RA (1974) Viscoelastic behavior and analysis of composite materials. In: Sendeckyj GP (ed) Composite materials vol 2: mechanics of composite materials. Academic, New York, pp 85-168
15. Cantey DE (1965) Solid propellant structural integrity investigations: dynamic response and failure mechanisms. Lockheed Propulsion Co., Redlands, Report no. AFRPL-TR-65-20

16. Loginov NP, Muratov SM, Nazarov NK (1976) Initiation of explosion and kinetics of explosive decomposition under vibration. Combust Explos Shock Waves 12:367-370

17. Hufferd WL, Fitzgerald JE (1976) Development of a solid propellant viscoelastic dynamic model

18. Taylor W, Weale A (1932) The mechanism of the initiation and propagation of detonation of solid explosives. Proc R Soc Lond A $138: 92-116$

19. Taylor W, Weale A (1938) Conditions for the initiation and propagation of detonation in solid explosives. Trans Faraday Soc 34:0995-1003

20. Bowden FP, Gurton OA (1948) Initiation of explosions by grit particles. Nature 162:654-655

21. Walley SM, Field JE, Greenaway MW (2006) Crystal sensitivies of energetic materials. Mater Sci Technol 22:402-413

22. Walley SM, Field JE, Biers RA, Proud WG, Williamson DM, Jardine AP (2015) The use of glass anvils in drop-weight studies of energetic materials. Propellants Explos Pyrotech 40:351-365

23. Matuszak ML, Upham DL, Hildner RA, Shaw MT (1981) The dynamic shear storage modulus of plastic-bonded explosives and its relationship to sensitivity. Propellants Explos Pyrotech 6:161-165

24. Rao BN (1992) Fracture of solid rocket propellant grains. Eng Fract Mech 43:455-459

25. Palmer SJP, Field JE, Huntley JM (1993) Deformation, strengths and strains to failure of polymer bonded explosives. Proc R Soc Lond A 440:399-419

26. Rae PJ, Goldrein HT, Palmer SJP, Field JE, Lewis AL (2002) Quasistatic studies of the deformation and failure of $\beta$-HMX based polymer bonded explosives. Proc R Soc Lond A 458:743-762

27. Rae PJ, Palmer S, Goldrein HT, Lewis AL, Field JE (2004) White-light digital image cross-correlation (DICC) analysis of the deformation of composite materials with random microstructure. Opt Lasers Eng 41:635-648

28. Welle EJ, Molek CD, Wixom RR, Samuels P (2014) Microstructural effects on the ignition behavior of HMX. J Phys 500:052049

29. Austin RA, Barton NR, Howard WM, Fried LE (2014) Modeling pore collapse and chemical reactions in shock-loaded HMX crystals. J Phys 500:052002

30. Rai NK, Koundinyan SP, Sen O, Schweigert IV, Henson BF, Udaykumar HS (2020) Evaluation of reaction kinetics models for meso-scale simulations of hotspot initiation and growth in HMX. Combust Flame 219:225-241

31. Zhou T, Lou J, Zhang Y, Song H, Huang F (2016) Hot spot formation and chemical reaction initiation in shocked HMX crystals with nanovoids: a large-scale reactive molecular dynamics study. Phys Chem Chem Phys 18:17627-17645

32. Horie Y (2014) Hot spots, high explosives ignition, and material microstructure. Mater Sci Forum 767:3-12

33. Kim S, Barua A, Horie Y, Zhou M (2014) Ignition probability of polymer-bonded explosives accounting for multiple sources of material stochasticity. J Appl Phys 115:174902

34. Barua A, Zhou M (2011) A Lagrangian framework for analyzing microstructural level response of polymer-bonded explosives. Modell Simul Mater Sci Eng 19:055001

35. Hardin DB, Zhou M (2017) Effect of viscoplasticity on ignition sensitivity of an HMX-based PBX. AIP Conf Proc 1793:080005

36. Duarte CA, Grilli N, Koslowski M (2018) Effect of initial damage variability on hot-spot nucleation in energetic materials. J Appl Phys 124:025104 
37. Herder G, Weterings FP, de Klerk WPC (2003) Mechanical analysis on rocket propellants. J Therm Anal Calorim 72:921-929

38. Cerri S, Bohn MA, Menke K, Galfetti L (2013) Aging of HTPB/ Al/AP rocket propellant formulations investigated by DMA measurements. Propellants Explos Pyrotech 38:190-198

39. Trache D, Khimeche K (2013) Study on the influence of ageing on chemical and mechanical properties of $N, N^{\prime}$-dimethyl- $N, N^{\prime}$ diphenylcarbamide stabilized propellants. J Therm Anal Calorim 111:305-312

40. Bihari BK, Wani V, Rao N, Singh P, Bhattacharya B (2014) Determination of activation energy of relaxation events in composite solid propellants by dynamic mechanical analysis. Def Sci J 64:173

41. Cegla M, Zmywaczyk J, Koniorczyk P (2018) Alternative method of determination of thermophysical properties of energetic materials. AIP Conf Proc 1988:020008

42. Cegla M, Zmywaczyk J (2018) Koniorczyk P (2018) Glass transition temperature determination of solid rocket propellants using various thermal analysis techniques. Thermophysics 1988:209

43. Shelley JS (2000) Smart structures for rocket propulsion systems. Air Force Research Laboratory, Edwards Airforce Base, Report no. AFRL-PR-ED-TP-2000-174

44. Sirkis J, Childers B, Melvin L, Peng T, Tang Y, Moore JJ, Enright E, Bovier C (1999) Integrated Vehicle Health Management (IVHM) on space vehicles: a space shuttle flight experiment. Key Eng Mater 167:273-280

45. Loginov NP, Surkova SN (2006) Effectiveness of phlegmatizers in explosive compositions under mechanical loading. Combust Explos Shock Waves 42:88-93

46. Koldyshev A, Grishkin A, Fil'chakov A, Krasnov V (1995) Ways of reducing the sensitivity of hexogen-bearing explosives to mechanical loads. Combust Explos Shock Waves 31:734-737

47. Lin CM, Liu JH, He GS, Chen LL, Huang Z, Gong FY, Liu YG, Liu SJ (2015) Non-linear viscoelastic properties of TATB-based polymer bonded explosives modified by a neutral polymeric bonding agent. RSC Adv 5:35811-35820

48. Lin CM, He GS, Liu JH, Pan LP, Liu SJ, Li J, Guo SY (2018) Construction and non-linear viscoelastic properties of nanostructure polymer bonded explosives filled with graphene. Compos Sci Technol 160:152-160

49. Williams ML, Landel RF, Ferry JD (1955) The temperature dependence of relaxation mechanisms in amorphous polymers and other glass-forming liquids. J Am Chem Soc 77:3701-3707

50. Schapery RA (1964) Effect of cyclic loading on the temperature in viscoelastic media with variable properties. AIAA J 2:827-835

51. Ratner SB, Korobov VI (1965) Self-heating of plastics during cyclic deformation. Polym Mech 1:63-68

52. Ratner SB, Korobov VI (1965) Spontaneous heating in a polymer during repeated deformation. Sov Phys Dokl 10:361-363

53. Knauss WG (1966) Time-dependent failure of viscoelastic materials under cyclic loads. In: Proc. 5th Meeting Interagency Rocket Propulsion Group: Working Group on Mechanical Behavior (CPIA Publication 119. Vol. 1) pp. 597-614. Silver Spring, Chemical Propulsion Information Agency

54. Savkin VG, Belyi VA, Sogolova TI, Kargin VA (1966) Effect of supermolecular structures on the self-heating of plastics under cyclic loads. Polym Mech 2:501-505

55. Johnsson A (1973) Temperature fields due to thermomechanical coupling in a compressible viscoelastic sphere. Acta Mech 17:201-209

56. Ting EC, Tuan JL (1973) Dissipative heating in a viscoelastic material due to cyclic pressure. Trans Soc Rheol 17:209-225
57. Karnaukhov VG, Yakovlev GA, Goncharov LP (1975) Self-heating of viscoelastic materials under cyclic loads. Strength Mater 7:164-168

58. Haward RN (1994) Heating effects in the deformation of thermoplastics. Thermochim Acta 247:87-109

59. Senchenkov IK, Karnaukhov VG (2001) Thermomechanical behavior of nonlinearly viscoelastic materials under harmonic loading. Int Appl Mech 37:1400-1432

60. Senchenkov IK, Zhuk YA, Karnaukhov VG (2004) Modeling the thermomechanical behavior of physically nonlinear materials under monoharmonic loading. Int Appl Mech 40:943-969

61. Lesieutre GA, Govindswamy K (1996) Finite element modeling of frequency-dependent and temperature-dependent dynamic behavior of viscoelastic materials in simple shear. Int J Solids Struct 33:419-432

62. Dinzart F, Molinari A, Herbach R (2008) Thermomechanical response of a viscoelastic beam under cyclic bending; self-heating and thermal failure. Arch Mech 60:59-85

63. de Cazenove J, Rade DA, de Lima AMG, Araújo CA (2012) A numerical and experimental investigation on self-heating effects in viscoelastic dampers. Mech Syst Signal Process 27:433-445

64. Muliana A (2014) Nonlinear viscoelastic-degradation model for polymeric based materials. Int J Solids Struct 51:122-132

65. Krairi A, Doghri I (2014) A thermodynamically-based constitutive model for thermoplastic polymers coupling viscoelasticity, viscoplasticity and ductile damage. Int J Plast 60:163-181

66. Shojaei AK, Volgers P (2017) Fatigue damage assessment of unfilled polymers including self-heating effects. Int J Fatigue 100:367-376

67. Chen KJ, Kang GZ, Lu FC, Chen J, Jiang H (2016) Effect of relative humidity on uniaxial cyclic softening/hardening and intrinsic heat generation of polyamide- 6 polymer. Polym Testing 56:19-28

68. Owen MJ, Dukes R (1967) Failure of glass-reinforced plastics under single and repeated loading. J Strain Anal 2:272-279

69. Tamuzh VP (1977) Fracture and fatigue of polymers and composites (survey). Polym Mech 13:392-408

70. Senchenkov IK, Zhuk YA, Chervinko OP (2001) Thermomechanical coupling effects near defects in inelastic bodies. Int Appl Mech 37:913-920

71. Chervinko OP (2004) Calculating the critical parameters characterizing the thermal instability of a viscoelastic prism with a stress concentrator under harmonic compression. Int Appl Mech 40:916-922

72. Chervinko OP, Senchenkov IK, Yakimenko NN (2007) Vibrations and self-heating of a viscoelastic prism with a cylindrical inclusion. Int Appl Mech 43:647-653

73. Dolya EV, Chervinko OP, Senchenkov IK (2007) Vibrations and self-heating of a layered elastic-viscoelastic rectangular prism under a vibrating punch. Int Appl Mech 43:886-892

74. Khan KA, Muliana AH (2012) Fully coupled heat conduction and deformation analyses of visco-elastic solids. Mech TimeDepend Mater 16:461-489

75. Khan KA (2011) A multiscale model for coupled heat conduction and deformations of viscoelastic composites. PhD thesis, Texas A\&M University

76. Khan KA, Muliana AH (2012) Fully coupled heat conduction and deformation analyses of nonlinear viscoelastic composites. Compos Struct 94:2025-2037

77. Kwak GH, Inoue K, Tominaga Y, Asai S, Sumita M (2001) Characterization of the vibrational damping loss factor and viscoelastic properties of ethylene-propylene rubbers reinforced with micro-scale fillers. J Appl Polym Sci 82:3058-3066

78. Drozdov AD (2011) Cyclic viscoelastoplasticity and lowcycle fatigue of polymer composites. Int J Solids Struct 48:2026-2040 
79. Meneghetti G, Quaresimin M (2011) Fatigue strength assessment of a short fiber composite based on the specific heat dissipation. Compos Part B-Eng 42:217-225

80. Eftekhari M, Fatemi A (2016) On the strengthening effect of increasing cycling frequency on fatigue behavior of some polymers and their composites: experiments and modeling. Int $\mathbf{J}$ Fatigue 87:153-166

81. Mortazavian S, Fatemi A (2017) Fatigue of short fiber thermoplastic composites: a review of recent experimental results and analysis. Int J Fatigue 102:171-183

82. Katunin A, Fidali M (2012) Fatigue and thermal failure of polymeric composites subjected to cyclic loading. Adv Compos Lett 21:63-69

83. Katunin A, Wronkowicz A, Bilewicz M (2017) Evaluation of critical self-heating temperature of composite structures based on analysis of microcrack development. Compos Theory Pract 17:9-13

84. Katunin A, Wachla D (2019) Determination of fatigue limit of polymeric composites in fully reversed bending loading mode using self-heating effect. J Compos Mater 53:83-91

85. Katunin A (2019) Criticality of the self-heating effect in polymers and polymer matrix composites during fatigue, and their application in non-destructive testing. Polymers. https://doi. org/10.3390/polym11010019

86. Naderi M, Khonsari MM (2013) On the role of damage energy in the fatigue degradation characterization of a composite laminate. Compos Part B-Eng 45:528-537

87. Magi F, Di Maio D, Sever I (2016) Damage initiation and structural degradation through resonance vibration: application to composite laminates in fatigue. Compos Sci Technol 132:47-56

88. Montesano J, Fawaz Z, Bougherara H (2013) Use of infrared thermography to investigate the fatigue behavior of a carbon fiber reinforced polymer composite. Compos Struct 97:76-83

89. Loginov NP, Muratov SM, Nazarov NK (1978) Effects of vibration on slow decomposition and explosion initiation for a solid explosive. Combust Explos Shock Waves 14:677-679

90. Loginov NP, Epifanov VB, Muratov SM (1984) Chemical decomposition of 2,4,6-trinitrotoluene in the presence of vibration. Combus Explos Shock Waves 20:683-685

91. Loginov NP, Muratov SM, Epifanov VB (1988) Vibrationinduced decomposition of trinitrobenzene. Combust Explos Shock Waves 24:120-122

92. Loginov NP, Muratov SM, Epifanov VB (1989) Decomposition of ammonium-perchlorate under vibration. Combust Explos Shock Waves 25:58-61

93. Loginov NP (1993) Vibration-induced decomposition of lead azide. Combust Explos Shock Waves 29:497-500

94. Loginov NP (1995) Vibration sensitivity of solid explosives. Combust Explos Shock Waves 31:94-99

95. Loginov NP (1997) Structural and physicochemical changes in RDX under vibration. Combust Explos Shock Waves 33:598-604

96. Loginov NP (2000) Criteria for estimation of explosion hazard in producing and processing explosives under vibration. Combust Explos Shock Waves 36:633-638

97. Loginov NP (2009) Decomposition of lead azide, pentaerythrite tetranitrate, and a laminate system composed of these substances under vibrational loading. Combust Explos Shock Waves 45:64-69

98. Wani V, Mehilal M, Jain S, Singh PP, Bhattacharya B (2012) Studies on the influence of testing parameters on dynamic and transient properties of composite solid rocket propellants using a dynamic mechanical analyzer. J Aerosp Technol Manag $4: 443-452$

99. Lee J, Soutis C (2008) Measuring the notched compressive strength of composite laminates: specimen size effects. Compos Sci Technol 68:2359-2366

100. Liu T, Sun BZ, Gu BH (2018) Effects of yarn defects and specimen size on impact compressive damages of 3D angle interlock woven composites. Int J Damage Mech 27:1380-1396

101. Kawai M, Watanabe K, Hoshi H, Hara E, Iwahori Y (2019) Effect of specimen size on longitudinal strength of unidirectional carbon/epoxy composite laminates (part 1, unnotched strength). Adv Compos Mater 28:53-71

102. Kawai M, Watanabe K, Hoshi H, Hara E, Iwahori Y (2019) Effect of specimen size on longitudinal strength of unidirectional carbon/epoxy composite laminates (part 2, splitting strength). Adv Compos Mater 28:73-100

103. Yilmaz O (2012) Service life assessment of solid rocket propellants considering random thermal and vibratory loads. Thesis, Middle East Technical University, Ankara, Turkey, MSc

104. Shou ZY, Chen FL, Yin HM (2018) Self-heating of a polymeric particulate composite under mechanical excitations. Mech Mater 117:116-125

105. Paripovic J, Davies P (2013) Identification of the dynamic behavior of surrogate explosive materials. In: ASME 2013 International Design Engineering Technical Conferences and Computers and Information in Engineering Conference. New York, American Society of Mechanical Engineers. Paper V008T13A066.

106. Miller JK, Woods DC, Rhoads JF (2014) Thermal and mechanical response of particulate composite plates under inertial excitation. J Appl Phys 116:244-904

107. Woods DC, Miller JK, Rhoads JF (2015) On the thermomechanical response of HTPB-based composite beams under near-resonant excitation. J Vib Acoust 137:054502

108. Mares JO, Miller JK, Sharp ND, Moore DS, Adams DE, Groven LJ, Rhoads JF, Son SF (2013) Thermal and mechanical response of PBX 9501 under contact excitation. J Appl Phys 113:084904

109. Miller JK, Mares JO, Gunduz IE, Son SF, Rhoads JF (2016) The impact of crystal morphology on the thermal responses of ultrasonically-excited energetic materials. J Appl Phys 119:024903

110. Roberts ZA, Mares JO, Miller JK, Gunduz IE, Son SF, Rhoads JF (2017) Phase changes in embedded HMX in response to periodic mechanical excitation. In: Challenges in mechanics of time dependent materials, vol 2. Springer, pp. 79-86

111. Czerski H, Greenaway MW, Proud WG, Field JE (2004) Monitoring phase change in HMX during dropweight impact. AIP Conf Proc 706:771-774

112. Roberts ZA, Casey AD, Gunduz IE, Rhoads JF, Son SF (2017) The effects of crystal proximity and crystal-binder adhesion on the thermal responses of ultrasonically-excited composite energetic materials. J Appl Phys 122:244901

113. Duarte CA, Kohler R, Koslowski M (2018) Dynamic fracture and frictional heating due to periodic excitation in energetic materials. J Appl Phys 124:165109

114. Grilli N, Duarte CA, Koslowski M (2018) Dynamic fracture and hot-spot modeling in energetic composites. J Appl Phys 123:065101

115. You SZ, Chen MW, Dlott DD, Suslick KS (2015) Ultrasonic hammer produces hot spots in solids. Nat Commun. https://doi. org/10.1038/ncomms 7581

Publisher's Note Springer Nature remains neutral with regard to jurisdictional claims in published maps and institutional affiliations. 